\title{
La reconstrucción: la Jota entre la marginalidad y el derecho a soñar (1994-1999)
}

\author{
The reconstruction: the Jota between the marginality and the \\ right to dream (1994-1999)
}

\author{
Fernando Pairican Padilla1 \\ Universidad de Santiago de Chile, Chile \\ fernandopairican@gmail.com
}

\begin{abstract}
Resumen
El presente artículo aborda la historia de las Juventudes Comunistas de Chile (JJ.CC) ${ }^{2}$, una vez superada "la gran crisis" que vivió entre 1989 y 1992. Hemos sostenido, que la capacidad de sobrevivencia de esta organización fue apostando por la defensa de su identidad comunista, encerrándose en sí misma. Superada esta etapa, la JJ.CC, comenzó un proceso de reconstrucción a partir de una inserción en el movimiento estudiantil, que no estuvo exenta de disputas en su interior. ¿Cómo lo hizo? ¿cuáles fueron sus estrategias utilizadas? ¿cómo una juventud con una retórica de la Guerra Fría logró convertirse en la principal fuerza estudiantil y cuestionar los pilares de la educación de mercado? Nuestra hipótesis plantea que, ante la marginalidad política, la Jota se insertó en los nuevos movimientos sociales que emergieron como protesta al despliegue del neoliberalismo, llevando a su conglomerado a rediseñar sus estrategias políticas y brindándoles un nuevo tipo de experiencia. Aquella dialéctica, entre nuevos movimientos sociales y la organización juvenil del Partido Comunista, bajo una expansión del neoliberalismo corregido, generó un aprendizaje en sus miembros, adaptándose a las nuevas transformaciones estructurales de la sociedad postpinochet. A nuestro parecer, durante los últimos años del siglo XX, la JJ.CC, transitó desde una perspectiva testimonial a una propositiva que llamaron Ruptura Democrática.
\end{abstract}

\section{Palabras Clave}

Juventudes Comunistas; Partido Comunista; identidad; renovación

\footnotetext{
${ }^{1}$ Chileno. Magíster en Historia de América, Candidato a Doctor en Historia, Universidad de Santiago de Chile. Este artículo es parte del proyecto FONDECYT no 1150583, titulado "Partido Comunista de Chile: Cambios y continuidades de su imaginario y cultura política (1990-2010)". El autor agradece los comentarios y aportes de los profesores Raquel Aranguez, Jorge Navarro López y José Ignacio Ponce.

2 En adelante Jota o JJ.CC.

Esta obra está sujeta a la Licencia Reconocimiento-NoComercial-CompartirIgual 4.0 Internacional de Creative Commons. http://creativecommons.org/licenses/by-nc-sa/4.0/ 


\title{
Fernando Pairican Padilla
}

\begin{abstract}
This entry broaches the history of the chilean Juventudes Comunistas once beated "the big crisis" (1989-1992). We have maintained that the survival capacity of "the Jota" was acchieved by making a bet for they own communist identity, shutting themselves in. Surpassed this stage, "the Jota" started it's reconstruction process, waging for politicize the Superior Education centers. A bet that wasn't exempt of controversy inside the own conglomerate. However, in it's médium term, that bet gave it's own products and allowed "the Jota" to turn into a protagonic actor of the students movement. How "the Jota" did it? Which were its strategies? How a youth, with a Cold War rhethoric, managed to become in the students main force and question the mercantil education's mainstays? Our hypothesis stands that, facing the political marginalization, "the Jota" inserted itself in the new social movements that emerged as a protest in front of the neoliberalism unfolding, taking it's conglomerate to redesign its polytical strategies and giving them a new kind of experience. The dialectics between new social movements and the youth organization of the Partido Comunista generated a learning in their members, allowing them to traslate from a testimonial perspective to a propositional one. Its members called this process: Democratic Rupture.
\end{abstract}

\section{Keywords}

Communist Youth; Communist Party; identity; renewal

\section{La reconstrucción 1994-1996}

\author{
Prometo educarme en las concepciones de \\ Marx, Engels, Lenin, Luis Emilio Recabarren \\ $y$ de otros pensadores marxistas \\ y progresistas de América Latina \\ $y$ del mundo y del internacionalismo proletario.
}

(Promesa militante de JJ.CC)

Ernesto "Che" Guevara, fue la figura que la militancia comunista tomó como eje central para prolongar su identidad. Sus escritos, su carisma y trayectoria política, fue adaptada por la Jota como el reflejo de lo que debería ser un verdadero comunista. En una nota de prensa del órgano oficial del Partido, se explicaba, a partir de la reedición de El cuadro, columna vertebral de la Revolución, que este "escrito no intenta establecer norma alguna atemporal sobre este tema clave para la vida de un partido revolucionario. Por el contrario, Ernesto Guevara lo aborda sobre las bases concretas de necesidades que exigía el proceso en curso en Cuba. Sin embargo, hay en el artículo elementos que el Che analiza y que pueden ser rescatados y revalorizados hoy"3.

Pocos meses después, uno de los intelectuales orgánicos importantes del Partido Comunista y miembro de su Comité Central, Juan Andrés Lagos, escribió

\footnotetext{
${ }^{3}$ El Siglo, “El cuadro, columna vertebral de la Revolución”. Marzo de 1994. P 10-11.
} 


\section{La reconstrucción: la Jota entre la marginalidad y el derecho a soñar (1994- 1999)}

Células y lucha de masas. En el texto hac un llamado a la militancia comunista a teorizar sobre los procesos sociales que estaban participando, para poder realizar mejores diagnósticos como partido. "Reflexionen sobre su propio quehacer", decía en abril de 1994, ${ }^{4}$ relevando la importancia en la formación de cuadros, lo que nos hace pensar que la sangría por la pérdida de militantes aún no cerraba. A tal punto, que durante el IX Congreso de la Jota, uno de los temas centrales fue "la falta de cuadros (...)" y señalaban: "esto pone al centro la labor de la educación, desarrollando distintos aspectos de ella". En este vacío, Guevara fue interpretado como el cuadro ideal, el sujeto que unió la práctica y la teoría, prolongando la subjetiva de la PRPM. Aquello no fue algo particular del comunismo chileno, como ha dicho el principal biógrafo de Guevara, en los noventa resurgió, luego de un olvido en las dos décadas anteriores, "como símbolo perdurable de combate intransigente contra un poder arraigado" 5 .

Desde nuestra óptica, rescatar la figura del Che, simbolizaba para fines del siglo XX, un amplio abanico de particularidades para la Jota. En primera instancia, el internacionalismo y latinoamericanismo, la entrega a tiempo completo a la militancia, una ética y compromiso con la transformación del escenario actual. Adaptado para un contexto democrático, la lucha armada como método quedaba descartada. Su figura, para los 90', fue enarbolado como la mística y el compromiso comunista con las transformaciones estructurales de la sociedad, en algún sentido, la conquista de una democracia radical ${ }^{6}$.

Desde el imaginario, nos parece que su figura se vincula con la prolongación de la Política de Rebelión Popular de Masas. Esta política, elaborada por el comunismo chileno para derrocar a la dictadura, incorporó la lucha armada como instrumento político. Ello marcó una renovación política en la historia del comunismo criollo, partido que, desde su nacimiento en la década del veinte, apostó por una vía electoral como manera de construir el socialismo sin abandonar las movilizaciones sociales, como las huelgas y marchas civiles. La cima de esta forma de hacer política fue sin duda la Vía Chilena al Socialismo encabezada por Salvador Allende ${ }^{7}$.

Sin embargo, el golpe de Estado, el proceso de persecución política contra su militancia, la vida clandestina y las torturas en los campos de concentración de la dictadura militar, crearon un "contrapunto" que produjo una nueva subjetividad. Una de ellas, para Álvarez, fue la legitimidad del componente armado para revertir el proceso de exterminó que estaba viviendo la militancia comunista ${ }^{8}$.

\footnotetext{
${ }^{4}$ El Siglo, "Células y lucha de masas". Abril de 1994. P 3.

${ }^{5}$ El Siglo, "La Jota camina al IX Congreso". Abril de 1994. Jon Lee Anderson, Che Guevara. Una vida revolucionaria. Anagrama, 2016. P 703.

${ }^{6}$ Ernesto Laclau y Chanta Mouffe, Hegemonía y estrategia socialista. Hacia una radicalización de la democracia. Fondo de la Cultura Económica, 2006.

${ }^{7}$ Para mayor profundización: Jorge Navarro, Parlamentarios y Revolucionarios. La cultura política del Partido Obrero Socialista. LOM Ediciones, 2017.

8 Rolando Álvarez, Desde las sombras. Una historia de la clandestinidad comunista (1973-1980).

Ediciones LOM, 2003.
} 


\section{Fernando Pairican Padilla}

En esa misma óptica, Bravo, lo refuerza a partir del ascenso de las protestas populares a consecuencia de la crisis económica de principios de los 80' en Chile, que mostraron los primeros síntomas de agotamiento de la dictadura. La masividad que adquirieron las protestas, reflejó, para algunos, las primeras grietas de la dictadura militar y, por ende, el componente militar habría tenido el espacio de legitimidad para derrocar a la dictadura a través de una insurrección popular de masas. Más que una guerrilla de carácter foquista, el Partido Comunista, analizaba el proceso como un amplio movimiento social donde el componente armado sería el encargado de modificar la correlación de fuerza en la lucha contra la dictadura. El fracaso de la Operación Siglo XX, en algún sentido, selló el destino de la salida insurreccional, por lo menos para el Partido Comunista de Chile9.

¿Es viable plantear que la militancia de las Juventudes Comunistas prolongó en algún sentido la PRPM? A nuestro parecer en algunos grados si es viable. La militancia comunista, a partir del plebiscito, descartó la lucha armada como instrumento político, aquello no significó que otros comunistas no lo creyeran, en ese ámbito radica, entre otras variables, el quiebre al interior del Frente Patriótico Manuel Rodríguez a partir de 1987. Desde esa arista, no existe una continuidad.

No obstante, la prolongación está en el plano de la subjetividad de la militancia. Para los últimos años del siglo XX, la cantera de militantes de las Juventudes Comunistas de Chile, siguió siendo una historia familiar, padres, madres, abuelos y abuelas, con historia comunista. Muchos vivieron los rigores de la dictadura, otros lucharon en la opción más radical contra la dictadura. Janette Jara, miembro de la JJ.CC, dice que en su población gran parte de sus amigos fueron miembros del MIR, Lautaro y sobre todo del FPMR, no era simple romper dichos lazos barriales. Ella misma reconoce que llegó a la USACH a estudiar bajo esa impronta ${ }^{10}$.

En ese ámbito, vemos una continuidad en la perspectiva del militante, como un actor entregado a la causa del Partido Comunista, un cuadro para la transformación social y radical, pero adaptado al contexto democrático. A nuestro parecer, aquello se simbolizó en el concepto de Revolución Democrática, nombre que adoptó la línea del PC chileno en la década de 1990. Según los comunistas, esta propiciaría una Ruptura Democrática a través de la generación de un amplio movimiento social que tuviera como fin una democracia plena y un Estado garante de derechos fundamentales. En otras palabras, una democracia radical.

En ese espacio, la figura del Che lograba reunir una mística, radicalidad y la continuidad de una figura del comunismo internacional, que, como ha dicho Anderson, respondió a un fenómeno mundial. Aquello, explicaría la simpatía que tuvo el zapatismo al interior del Partido Comunista y de sus Juventudes: una lucha armada que nació para radicalizar la democracia.

\footnotetext{
9 Viviana Bravo, ;Con la Razón y la Fuerza, Venceremos! La Rebelión Popular y la Subjetividad Comunista en los '80. Editorial Ariadna, 2010. La Operación Siglo XX fue el intento de asesinar al dictador en una emboscada.

10 Entrevista a Janette Jara.
} 


\section{La reconstrucción: la Jota entre la marginalidad y el derecho a soñar (1994- 1999)}

¿Cómo hicieron los jóvenes comunistas para conquistar lo que Francisco Villa -un joven trovador comunista- llamó como el "derecho a soñar? ¿Qué estrategias utilizaron públicamente para no aparecer como jóvenes conservadores, con un discurso del siglo XX cuando el siglo XXI y la globalización se apoderaban de la juventud? Este apartado busca responder a estas preguntas.

Las Juventudes Comunistas fueron tal vez uno de los primeros conglomerados juveniles de izquierda en comprender la dimensión de la derrota política provocada por la dictadura militar. Su principal diagnóstico se enfocó en la incapacidad del modelo económico de cumplir las promesas entorno a los derechos fundamentales que el Estado debería garantizar para su desarrollo. La entrega de los derechos básicos al libre mercado, por parte de los gobiernos de la Concertación, fue lo que aglutinó a la juventud comunista y los cohesionó para sobrevivir en una década donde, su marginalidad política -si la comparamos con su historia previa al derrumbe del socialismo real-, era evidente. La JJ.CC, en ese aspecto, se aglutinó en torno a lo que llamaron como "la batalla por la educación". Su objetivo: politizar a los jóvenes de la recién recuperada democracia y, como dijera Francisco Villa, a no dejarse "arrastrar por la corriente", "ser digno" y llevar la "frente en alto"11.

En este proceso, mientras el consumo se convertía en una matriz de la sociedad chilena, hechos internacionales remecieron la subjetividad de la JJ.CC, en particular la rebelión maya en el Estado de Chiapas, a principios de 1994, la que fue bautizada por ellos como la primera "Revolución del siglo XXI"12.

Gladys Marín, una de los principales referentes del PCCh, vio en el zapatismo la síntesis de la línea estratégica que se debatía al interior de su partido: variable indígena, conquista de espacios democráticos, radicalidad, ética política y anti neoliberalismo. Todos estos factores, además de los propios diagnósticos interiores, nos parece que influyeron para que Gladys Marín, diera a conocer que la política del comunismo chileno bajo el gobierno de Eduardo Frei, sería crear "focos de resistencia al modelo neoliberal". ${ }^{13} \mathrm{El}$ EZLN, en algún sentido permitía un nuevo espacio de maniobra política a nivel internacional.

Para las Juventudes Comunistas de Chile, la cultura era uno de sus epicentros fundamentales donde se revertiría el modelo neoliberal. Para lograrlo, se debía crear una síntesis de lo mejor forjado por el movimiento popular previo al golpe de Estado de 1973. Era una apuesta nostálgica, pero que buscaba recuperar una tradición comunista, adaptándose a los cambios culturales en el país. Para tales

\footnotetext{
${ }^{11}$ Francisco Villa, "Mi derecho a soñar". Sello Alerce, 2000. El concepto de la "batalla” comenzó a ser recurrente en las entrevistas a los miembros de la Jota. Desde nuestra óptica ello responde a la influencia de la Revolución Cubana, en particular, los discursos de Fidel Castro bajo el "periodo especial" (1990-1995). A su vez, era la prolongación del lenguaje político de la PRPM. Sobre esto, revisar: Bravo Viviana, ¡Con la razón o la fuerza venceremos! La rebelión popular de masas y la subjetividad comunista de los 80. Ediciones Ariadna, 2015.

12 El Siglo, "La primera revolución del siglo XXI". 20 de marzo al 1 de abril 1994. P 3. En este mismo número, el artículo de José Ponce, "El internacionalismo latioamericanista del PC chileno en el mundo postsoviético (1988-1994).

13 El Siglo, “"Debemos levantar focos de resistencia al modelo". Enero de 1994, p 12; La Época,

“Comunistas auguran acentuación de contradicciones en la Concertación”. 14/02/1994. P14.
} 


\section{Fernando Pairican Padilla}

efectos, recuperar la nueva canción chilena, las compañías de teatro, la plástica y pintura popular, al mismo tiempo que se habrían los "brazos y cabezas a la 'anarquía organizada' de lo contestatario del comic y los grafitis", era un camino clave para revertir la cultura apolítica del neoliberalismo. Lo importante, decían las Juventudes Comunistas, era rechazar "la ideología neoliberal implantada por el fascismo", y sentar las bases para una Revolución Cultural que fortaleciese el "jaque mate al sistema". ${ }^{14}$

En una entrevista a Guillermo Salinas, secretario general de la organización hacia 1995, se presentaba como un abstemio, que en contadas ocasiones salía alguna fiesta, nunca había probado alguna droga, como la marihuana y su música favorita era la Trova Cubana y la Nueva Canción Chilena. Entre ellos, destacaban Silvio Rodríguez, Pablo Milanés y Víctor Jara. Políticamente, su admiración se inclinaba por Ernesto Guevara y Salvador Allende. Cuando la periodista, con algo de sarcasmo, le preguntó si no se sentían pegados al pasado, el dirigente respondía que eran estereotipos de una campaña con el fin de mostrarlos como personas ancladas en una "lucha antigua". Sin embargo, mientras que en lo cultura podría primar una tradición, a la hora de la política se presentaba perspectivas de futuro. El secretario de la JJ.CC, planteaba que sus objetivos eran avanzar en una movilización social que ayudara a romper las ataduras de la dictadura y de esa manera obtener una "democracia de verdad"15.

Daniel Núñez era miembro del Comité Central de la Jota y activo militante de la célula en la Universidad de Chile para 1994. La pérdida de militantes para esos años, había mermado las capacidades de injerencia en la política como actores protagónicos, acabando por quedar reducidos al mundo universitario en Santiago. De ahí que reconstruirse como organización y superar la etapa de sobrevivencia, fue una de las tareas fundamentales de la JJ.CC.

En sus reflexiones, el modelo económico se presentaba como inmutable, lo que provocaba en ellos una sensación de "desamparo político". Había que tener mucha convicción, pues todos sus planteamientos eran atacados de manera pública. En sus recuerdos, mantiene nítida la imagen cuando en plena clase de sociología, con el prestigioso Manuel Antonio Garretón, discutió el concepto de neoliberalismo. "Me atacó de manera muy fuerte”, recuerda, me dijo: “Neoliberalismo: no existe!”. La sola idea de plantear la prolongación del modelo económico de la dictadura por parte de los gobiernos post Pinochet, no tan solo era visto como un ataque, sino, como algo impensable. No obstante, hoy pocos discuten que no exista en materia económica una prolongación de la revolución económica forjada por el régimen militar, el mismo Garretón ha dicho que los gobiernos de la Concertación se han caracterizado por ser neoliberales, aunque, "corregidos"16.

\footnotetext{
14 "Anteproyecto del Programa de la Juventud". Mecanografiado. Este Anteproyecto fue el segundo punto del IX Congreso de la Jota a efectuarse entre junio y noviembre de 1994.

${ }^{15}$ La Nación, "No tengo cabeza de pistola". 22/02/1995.

${ }^{16}$ Entrevista a Daniel Núñez, marzo de 2016; Garretón Manuel, Neoliberalismo corregido y progresismo limitado. Los gobiernos de la Concertación en Chile, 1990-2010. Editorial ARCIS/CLACSO, 2012.
} 


\section{La reconstrucción: la Jota entre la marginalidad y el derecho a soñar (1994- 1999)}

Los miembros de la Jota recuerdan una orfandad teórica a inicios del gobierno de Eduardo Frei Ruiz-Tagle. Muchos de sus intelectuales estaban retirados desde la crisis de 1992, mientras que otros pensadores de izquierda, eran firmes defensores de los gobiernos de la Concertación. Núñez dice que fue recién en 1997, con la publicación del libro de Tomás Moulian Chile actual. Anatomía de un mito, que sintieron un respaldo a sus dudas ideológicas. En cierto aspecto, este libro se convirtió en cabecera de la JJ.CC. Años después, Núñez sintetizó su experiencia política en su tesis para titularse como sociólogo, titulada "El despertar del movimiento estudiantil". En ella, señala que el neoliberalismo no debe reducirse tan solo a una doctrina económica, pues ella se inspira en principios filosóficos y que "son empleados para orientar transformaciones estructurales en el ámbito social, político y cultural que llevan a la articulación de un nuevo orden social". Aquel orden, para Núñez, estaría dado por la naturalización de la desigualdad, el estricto orden a las reglas del mercado y la eliminación de toda función económica y social del Estado".17

Pero uno de los nudos políticos más trascendentales, estuvo sujeto a la decisión de abandonar momentáneamente los sectores poblaciones y obreros, para abocarse al mundo universitario. Para algunos un giro a la "derecha" de la JJ.CC, para otros, realismo político.

Sin embargo, para la militancia apostada sobre todo en la Universidad de Chile, sería en la educación superior, donde las ofertas, promesas y capacidad de cumplirlas, acabarían por demostrar la inviabilidad del modelo y, por lo tanto, los primeros síntomas de las fracturas del neoliberalismo.

Esta reflexión, se comenzó a desarrollar colectivamente en el transcurso de los últimos años del siglo XX, y fue una decisión pragmática. "No teníamos gente”, en voz de Daniel Núñez, por ende, “debíamos focalizar nuestra militancia en los espacios de oportunidad". Era un giro importante para un Partido clasista, donde la impronta subjetiva de la lucha contra la dictadura estaba justamente en los sectores populares. No fue hasta las movilizaciones de 1997 que las críticas fueron descendiendo, momento que la JJ.CC tomó un protagonismo que ni ellos mismos imaginaban.

Una de las militantes que vio de manera crítica este giro fue Janette Jara. Desde su óptica, apostar políticamente por un sector de clase media ponía en tensión la propia historia de "la Jota rebelde de los 80". No obstante, esa misma experiencia de politización popular, dice que contribuyó a brindarle a la JJ.CC de la USACH un aspecto más radical, que permitió abrir espacios de convergencias con la izquierda de corte más bien mirista. Una de sus primeras acciones en conjunto, fue crear Asambleas de Izquierda con el fin de discutir problemas o dificultades como estudiantes, una de ellas, las altas tasas de aranceles. Este proceso de concentización, como lo llama ella, terminó por crear una lista para ganar la

\footnotetext{
17 Núñez Daniel, “El despertar del movimiento estudiantil y la crisis de la universidad pública”. Tesis para optar a sociología. Universidad de Chile, 2003. P 39.
} 


\section{Fernando Pairican Padilla}

Federación de Estudiantes de la USACH (FEUSACH), la llamaron simplemente: "Izquierda".

En la Universidad de Chile, también se apostó por efectuar asambleas en torno a proteger el patrimonio de la Universidad. Poniendo demandas locales, con el fin de articularlas en procesos más amplios, la militancia comunista fue conquistando adeptos, hasta lograr encabezar la principal federación de estudiantes, la FECH en 1995, con el eslogan: "Estudiantes de Izquierda por la defensa de la U". ${ }^{18}$

Janette Jara dice que existía un discurso anticomunista muy fuerte de parte de los estudiantes, por ello, al igual que en la Universidad de Chile, crearon colectivos políticos sin afiliación partidaria. Esta estrategia les permitió ganar en las elecciones para gobernar FEUSACH durante el segundo año de retorno democrático, con la "Lista 91", el que fue precedido por Héctor Fuentes, acompañada además por dos miembros más de la JJ.CC: Lucio Cuenca y Luis Acuña ${ }^{19}$. Bajo su conducción, como manera de revertir los vacíos de la educación de mercado, las Juventudes Comunistas de Chile crearon un programa de Preuniversitarios. Se pensó para los estudiantes de menores recursos, para que pudiera incorporarse a la Educación Superior. Fue una construcción que apuntaba a demostrar los vacíos estatales, y que, en el camino, se transformó en una estrategia de hegemonía de la política comunista en la USACH. Sería, a partir de estas políticas sociales, que la JJ.CC, cuestionaría el neoliberalismo, generaría conciencia y atraería nuevos militantes para su conglomerado.

Como "Colectivo 91", Jara plantea que en algún momento abrieron la discusión a la comunidad educativa general en base a una pregunta: "cómo reconstruir el movimiento estudiantil desde las bases". Dice que llegaron estudiantes de distintas izquierdas, también personas no militantes, cerca de 80 o más. "Fue una pequeña victoria", rememora Ricardo Jara, y agrega: "se había logrado vencer al discurso instalado del no "estoy ni ahí". Mientras que Jara aporta con un aspecto subjetivo a partir de una historia. Con cariño, recuerda aquel momento en que se reunieron en un kiosko bajo los departamentos de la Villa Diego Portales a petición del encargado de la célula, quien llegó con una "Fanta" y unos pancitos, "yo le pregunté ¿qué onda? Y el compañero me respondió 'estamos celebrando'”. La otrora dirigente juvenil comunista rememora: "era una Jota que venía golpeada, pero que lograba de una u otra forma, mantener su subsistencia como juventud política y celebrar con ciertos hitos, mantuvo un poco la mística. Y sabes -enfatiza-, que ese pequeño acto entre nosotros mismo para mí fue muy significativo (...) ese acto nos dio un vínculo importante"20.

\footnotetext{
${ }^{18}$ La Nación, "JJ.CC. ganan en la FECH". 25/10/1995. Para profundizar: revisar el libro de Víctor Muñoz, Generaciones. Citado.

${ }^{19}$ La Tercera, “Comunistas ganan en la USACH”. 24/11/1990. P 13 . Fuentes triunfó con 2.090 votos, consigna el diario, compartiendo mesa con el militante demócrata cristiano Armando Pozo y el militante PPD Marcos Ramírez.

${ }^{20}$ Entrevistas a Ricardo Jara y Janette Jara. Enero y mayo de 2016.
} 


\section{La reconstrucción: la Jota entre la marginalidad y el derecho a soñar (1994- 1999)}

Como Jota, bajo el nombre de "Colectivo 91", siguieron trabajando y dieron vida a lo que llamaron "Asambleas de Izquierda". Al ir tomando mayor fuerza, decidieron retomar una vieja práctica estudiantil, importante en la mística comunista: los trabajos voluntarios. Durante todos los inviernos y veranos, los estudiantes que quisieran participar de la USACH, podrían viajar a algún lugar a experimentar el trabajo en sectores populares, como mapuche, campesinos o pescadores. Reconoce Janette Jara, que este se convirtió en el "semillero" de la nueva militancia. "Empezamos además a hacer reflexiones sobre lo que era el movimiento estudiantil, que se necesitaba y que se requería para su recomposición"21.

En esa misma línea, Marcos Barraza, recordó en una entrevista a fines de 1997, que partieron por cosas simples, como organizar la semana de bienvenida a los nuevos estudiantes, trabajos voluntarios, presentación de obras de teatro y semanas culturales. Dice que ello generó confianzas, respondiéndoles a un "universo de estudiantes que andan buscando dónde sentirse representados"22.

La propuesta de la Jota en torno al sistema educativo se basaba en revertir cualquier aspecto que posicionase lo económico por sobre lo social. La tarea por lo tanto fue derogar los DFL №4 creado en 1980 por la dictadura militar, y que se prolongó bajo los gobiernos de la Concertación. Estos Decretos de Fuerza de Ley, abrieron las puertas de la injerencia de la banca en materias competentes del Estado. Para la Jota, además de ser otro cimiento de la continuidad de la dictadura, puso a discusión la toma de decisiones en el ámbito universitario. En voz de Daniel Núñez, era urgente un gobierno universitario para evitar la hegemonía de los tecnócratas de la educación y ser escuchado como comunidad universitaria. Ambos eslabones, desde la perspectiva de la Jota, debían cimentarse en un movimiento estudiantil, romper el aislamiento de que las luchas universitarias son locales y meramente un asunto económico. Las universidades, sostenía Núñez, debían ser nuevamente consideradas como una "verdadera creadora de las riquezas espirituales del país"23.

En este mismo lapso de tiempo, en Santiago, tenues protestas en la Universidad de Chile y la Universidad Tecnológica Metropolitana, iniciaron un proceso de movilización por problemáticas internas que los militantes comunistas se encargaron de politizar suscribiéndolas a ejes estructurales. Eran las primeras señales de esas "fracturas" del modelo, como lo llamaban, en torno a la imposibilidad de cumplir las promesas de educación en base a las lógicas del mercado. Las razones de la movilización, no eran ideológicas, eran prácticas: las nuevas formas de abordar los pagos de las carreras al externalizar las deudas a la banca privada. Lo que antes era una responsabilidad del Estado, a mediados de los 90, fue asumida por la banca, elevando las tasas de intereses imposibles de ser abordados por familias de escasos

\footnotetext{
${ }^{21}$ Ibíd.

22 El Siglo, "Vamos a profundizar la lucha por los cambios". Noviembre de 1997.

${ }^{23}$ El Siglo, ¡A la defensa de la Universidad! Junio de 1994. P 13.
} 


\section{Fernando Pairican Padilla}

recursos e incipientes clases medias. La crítica al co-pago motivó a estas dos universidades a manifestarse ${ }^{24}$.

En una entrevista de mediados de 1994, Ricardo Jara (USACH) y Daniel Núñez (U.Chile), planteaban sobre la educación superior que esta, "en vez de ser un bien social -señalaban-, se convertirá en, prácticamente, un activo de mercado, donde los estudiantes serán clientes de las instituciones" 25 .

A modo de síntesis de este primer apartado, la reconstrucción de la Jota fue posible por la perpetuación de una identidad comunista que internacionalmente recuperó a Ernesto Guevara y nacionalmente perpetuó la subjetividad de la PRPM. En segundo aspecto, en la apuesta pragmática por abandonar momentáneamente los sectores vulnerados del modelo, por espacios donde las promesas neoliberales no serían capaces de cumplirse, mostrando sus primeras "fracturas". A partir de ello, se hizo un diagnóstico que fue teorizando tiempo después, no obstante, permitió dar rutas para llevar adelante el trabajo político. Ello se debió, además por las convergencias de distintas procedencias sociales e identidades comunistas, las que acabaron por complementarse y nutrir con sus experiencias este proceso que hemos llamado de reconstrucción.

Mientras esto sucedía, durante 1994, la agenda comunista estuvo marcada por los congresos que se realizan cada cuatro años. Ese año, el Partido se volcó hacia los movimientos sociales con el propósito de generar una Revolución Democrática, en el entendido para el PCCh, que, a partir de 1990, se habían abierto "espacios democráticos", pero aún se estaba lejos de una democracia plena. ¿Cómo se haría? Con una "ruptura democrática", que rompiera, en palabras Rolando Álvarez "el legado pinochetista". En ese ámbito, sostiene este historiador, se ve una continuidad con la PRPM porque significaba reconocer la "ilegitimidad del orden político, económico y social de la postdictadura". Ahora, ¿cómo se provocaría esa ruptura democrática? A partir de la inserción en los movimientos sociales contra el modelo, Volodia Teitelboim, anunciaba esto como el necesario "viraje" para modificar la situación política ${ }^{26}$.

Meses después, Gladys Marín, señalaba que la tarea era avanzar a una nueva Constitución, donde la soberanía de está recayera en el pueblo y para ello, lo prioritario era desmantelar el sistema binominal, ya que este permitía la representación de las fuerzas que "buscan mantener el actual sistema". Acompañado de este cambio político, Marín planteaba que se debía avanzar en una redistribución de los ingresos con participación de los trabajadores. "Hay que democratizar la calidad de vida de la gente y asegurar el acceso a los más elemental que requiere el ser humano, es decir, al acceso a la salud, la previsión, a la educación y a la vivienda". De alguna manera, para la dirigente, Revolución Democrática era reposicionar al

\footnotetext{
24 La Época, “Tomas indefinidas en U Tecnológica por demandas económicas”. 12/04/1994. P 17; El Siglo, "la movilización surgió desde las bases". Abril de 1994. P 12. Mayor profundización sobre las leyes y formas de pago relacionados con la Educación Superior, Thieleman Luis. Op.Cit. ${ }^{25}$ El Siglo, ¡A la defensa de la Universidad! Junio de 1994. P 13.

${ }^{26}$ Álvarez Rolando, Ibídem. P 157; El Siglo, Teitelboim Volodia, "Las responsabilidades del XVI Congreso". 25/06/1994. P 7
} 


\section{La reconstrucción: la Jota entre la marginalidad y el derecho a soñar (1994- 1999)}

Estado como garante de lo social y subrayaba: "ni siquiera hablamos de una democracia socialista, o una plena y absoluta, sino de una democracia liberal o burguesa"27.

Bajo este clímax, la Jota inauguró su IX congreso el 11 de junio de 1994. Luis Salinas, Secretario General, fue el principal orador en la jornada. Enfatizó en la urgencia de unir a los jóvenes detrás de una plataforma que reuniera las principales demandas de la juventud, las que indudablemente estaban vinculadas a las consecuencias del modelo económico y político que "posterga a la mayoría de las personas y busca disminuir el rol y el protagonismo juvenil". Arengaba a la militancia, a partir de los ejemplos de la Jota de la Universidad de Chile y USACH, que había logrado dar pasos importantes con las movilizaciones de abril y mayo, a superar la tendencia de la juventud a la depresión e inmovilismo social. ${ }^{28}$

Como era la tradición comunista, en la convocatoria al IX Congreso, la dirección de la Jota comenzó por realizar una autocrítica como organización, subrayando en las primeras páginas del documento las dificultades del periodo 1989-1994. La principal fue la reconstrucción de la Jota, luego de la crisis derivada del VIII Congreso y la masiva pérdida de militantes. Planteaban que esos aspectos, estaban superados, lo que no era cierto para fines de 1994. Retóricamente, señalaban que la instancia, era para "discutir cómo organizarnos para luchar más y mejor cada día tras el objetivo de elevar nuestra relación con los jóvenes"29.

A su vez, es posible vislumbrar a partir de su documentación, las tensiones en los rumbos que la dirección de la Jota por apostar al ámbito universitario en desmedro del territorio. Para comprender estas disputas, inexorablemente tenemos que analizar el contexto latinoamericano en que la dirección miraba con simpatía los procesos guerrilleros de Centroamérica. La derrota del sandinismo, el proceso de paz en Salvador y Guatemala, para la Jota respondía a la ofensiva del imperialismo y la crisis del socialismo real. Era el cierre de un período histórico, y lo que sucedió fue un "proceso de readecuación táctica y, en algunos casos, estratégica de los movimientos populares y guerrilleros del mundo". En ese mismo sentido, el zapatismo desde la óptica oficial de la Jota era la demostración de la vigencia de las guerrillas y que confirmaba otro aspecto crucial: "el camino sigue siendo la lucha" 30.

Desde este análisis, por ende, el giro político en defensa de la Educación Universitaria y de forzar una ruptura democrática a partir de las mismas contradicciones del modelo, mostraba la crítica de parte de los militantes apostados en los barrios populares, que a partir de su experiencia política de los 80' y de su admiración a las guerrillas de la misma década, habían sostenido la base de la PRPM. Ricardo Jara, el encargado estudiantil de la Jota, sin tapujos recuerda que no eran

\footnotetext{
27 Pluma y Pincel, “Un liderazgo para la Revolución Democrática”. №171. P 4.

${ }^{28}$ El Siglo, "Inician IX Congreso Nacional de la Jota”. Junio de 1994. P 16; “Comenzó el IX Congreso de la JJ.CC”. Junio-Julio 1994. P 13.

29 "Para crear y creer el futuro a organizar y lucha". Convocatoria al IX Congreso de la JJ.CC. Junionoviembre 1994. P 1-10.

30 Ibídem.
} 


\section{Fernando Pairican Padilla}

muy bien vistos, "no lo decían, pero ahí no les gustó para nada e inclusive a la Dirección del partido. Las dudas de los compañeros eran los temores de que esta visión pudiera terminar avalando las políticas del propio gobierno". ${ }^{1}$ Sin embargo, Luis Salinas era explícito: "un sector que tenemos que privilegiar es el movimiento estudiantil", tanto por ser una tradición organizativa como "por los elementos que hay de recomposición"32.

La dirección, para evitar nuevas fracturas, hizo un llamado explícito a la unidad y al compañerismo, señalando: "Todos somos jotosos y una victoria en el frente estudiantil es también una victoria de los jotosos del territorio, un logro en lo sindical es el triunfo también de los jotosos de la universidad". No obstante, a pocos años de terminarse el siglo XX, la Jota mantenía sus dos almas que, bajo un contexto democrático, por más que lo considerase insuficiente, eran contradictorias. Levantar un imaginario armado, para impulsar una acción que fuera desmantelando los amarres de la dictadura, muestra las complejidades del proceso histórico en curso en ellos mismos y de lo que llamaron como el "continuismo" con la administración anterior. Por ende, la tarea fundamental, era "cómo ayudamos a reponer y profundizar las luchas por las transformaciones democráticas que el país necesita"33.

En paralelo a este proceso en curso, Luis Salinas especificaba frente a los patriarcas del comunismo chileno en el XVI Congreso, que ser de la Jota no era por casualidad, era por convicción y confianza. Y señalaba: "hacerse comunista hoy, así como seguir siéndolo tiene quizás tanto valor como lo tuvo en su momento para quienes fundaron el Partido. Un joven comunista es un joven que se le arrebata al sistema y que se suma a las posibilidades de construir una sociedad distinta"34.

Para agosto de 1994, las piezas del tablero de ajedrez al interior del Partido Comunista estaban ya posicionadas. Gladys Marín triunfó en la interna asumiendo como flamante Secretaria General en desmedro de Jorge Insunza. Con ella, las tesis de oposición al modelo neoliberal y al gobierno, de las que la Jota simpatizaban absolutamente. Aspecto distinto de Insunza, para quien abrirse a espacios de convergencia con los sectores de izquierda de la Concertación no le eran contradictorios. Marín, una semana después enterró cualquier espacio a las dudas sobre esta materia al decir: "Yo no sé si alguien esperaba que en el partido se eligiera

\footnotetext{
31 Entrevista con Ricardo Jara. Citada.

32 El Siglo, "Hablamos de recuperar los espacios". Octubre de 1994. P 14.

33 "Para crear y creer el futuro a organizar y lucha". Convocatoria al IX Congreso de la JJ.CC. Junionoviembre 1994. P 1-10. Estas diferencias no se resolvieron. En 1996, Guillermo Salinas, cuadro obrero de la Jota escogido como Secretario general de la Jota, renuncia a la dirección para evitar una nueva crisis en el conglomerado. Asume la dirección Daniel Núñez, quien recuerda. "surge la idea de que hay que hacer cambios dentro de la dirección de la jota, el propio secretario general que era Guillermo Salinas, siente que ya cumplió la etapa y ahí comenzó el debate de hacer cambios y eso tensiona un poco a la dirección del partido porque estaba le temor de que hubieran fracciones, tendencias estudiantiles, de origen más popular, dentro de la dirección de la jota, y esa tensión... bueno genera harto intercambio, harto debate. Finalmente se resuelve aceptando que es un proceso normal y ocurre que el compañero Guillermo Salinas propone su salida y yo asumo como secretario general". Entrevista a Daniel Núñez, marzo de 2016.

34 El Siglo, "Saludos de las juventudes comunistas". Agosto de 1994. P 11.
} 


\section{La reconstrucción: la Jota entre la marginalidad y el derecho a soñar (1994- 1999)}

a una persona que al día siguiente declara que el PC entra a la Concertación. Eso no existe, ni existe el candidato para eso"35.

Otros de los cambios aparentemente cosméticos, fue la fecha de fundación del PCCh. A partir del XVI Congreso, el comunismo chileno se apoderaba del Partido Obrero Socialista, fundado por Luis Emilio Recabarren, quien, a su vez, provenía del Partido Demócrata. Desde nuestra óptica, la decisión estuvo supeditada a una "invención de la tradición", posicionar al Partido Comunista en una historia en la larga duración por abrir los espacios democráticos en la misma historia de Chile, como era resquebrajar el orden oligárquico heredado del siglo XIX. Así, el PCCh, de alguna manera reescribía su propia historia, se "desbolchevizaba" y se incorporaba como los principales artífices de las oberturas democráticas en la historia de Chile. Así lo miraba por lo demás uno de los personajes más importantes del Partido Comunista, Luis Corvalán quien señalaría para fines de 1999: "la izquierda ha sido fundamental en la historia de este país en este siglo que termina. Todos los avances democráticos de este sigo han sido gracias a la izquierda"36. Así, a partir de 1994, lo que comenzó como XVI Congreso acabó convirtiéndose en el número XX, fundamentando a nuestro parecer su nueva línea programática: la revolución democrática para el siglo XXI ${ }^{37}$.

En su primer discurso como Secretaria General, desde las dependencias del ex Congreso Nacional, Gladys Marín avisaba que, bajo su conducción, el comunismo chileno se caracterizaría por impulsar una acumulación de fuerzas para generar una alternativa de izquierda, cuyas características serían la confrontación, la ruptura y la desobediencia democrática ${ }^{38}$. Podría ser distinto, agregaba en una entrevista posterior, si la Concertación volvía a retomar el programa original del conglomerado redactado en $1988^{39}$.

El domingo 20 de noviembre de 1994, pasada las 19:00 horas, la Jota cerró su IX Congreso luego de cuatro días de cónclave. El humo blanco dio como resultado que, a partir de la elección de su Comité Central, las "almas" identitarias de la Jota seguían en pugna constructivamente. Si Luis Salinas había declarado que la lucha estudiantil era la prioritaria, las bases de la Jota ponían al debate dicha concepción, pues el nuevo Secretario General de la entidad fue un obrero: Guillermo Salinas. No obstante, en una segunda posición quedó el ala estudiantil, encabezada por Daniel Núñez.

De los cuarenta integrantes de la Comité Central, nueve fueron mujeres, seis pertenecían a las regiones y nueve miembros eran secretarios comunales de la Jota. Mientras que once de sus miembros continuaron en sus puestos. En cifras, el 64\%

\footnotetext{
35 La Época, “Gladys Marín: no somos ni duros ni blanduchos”. 22/08/1994.

${ }^{36}$ La Nación, "Aquí debe producirse un terremoto político". 1/11/1999. P 10.

37 La Época, "anoche el PC inició la etapa final de su 16을 Congreso". 12/08/1994; "El PC sólo admite matices, pero no formación de 'tendencias'”. 13/08/1994. Rolando Álvarez sostiene que respondía a su vez a la urgencia de desvincular sus orígenes a un proyecto histórico mundial que había terminado con el colapso de la URSS a comienzo de los noventa". Citado. P 148.

38 La Época, “Gladys Marín, tras ser elegida, reafirmó política rupturista del PC”. 14/08/1994.

39 La Época, “Gladys Marín: no somos ni duros ni blanduchos”. 22/08/1994.
} 


\section{Fernando Pairican Padilla}

del nuevo ente directivo de la organzanición fueron hombres y un 36\% mujeres. Mientras que el promedio de edad fue de 23 años.

Los aspectos simbólicos no quedaron ausentes en la jornada. Gladys Marín y Juan Andrés Lagos, entregaron al nuevo Comité Central una placa de la década de 1930, encontrada por un grupo de obreros en una demolición. Ellos la entregaron al Partido Comunista, quienes a su vez se la entregaban a la Jota como "testimonio de que ya en esos años había jóvenes revolucionarios organizados". ¿Cuál sería el comunista que ejemplificaría los cuatro años en adelante? Carlos Contreras, en su figura esperaba que el militante de la Jota sintiera un referente ${ }^{40}$.

\section{La sobrevivencia: 1997}

\section{Prometo conocer y defender el programa y la política del Partido Comunista de Chile, al cual aspiro a integrarme (Promesa militante)}

En la noche del 25 de abril, Guillermo Salinas dejó su responsabilidad como máximo dirigente de la Jota. Si meses antes las identidades de la Jota habían logrado equilibrio, aquella noche, el ala estudiantil decidió dar un golpe de timón al colocar en su lugar a Daniel Núñez. En un informe al XIV Pleno, argumentaron problemas principalmente de conducción, "existe -señalaba el informe-, una preocupación por el insuficiente rol que juega hoy el C.C, pue no ha logrado posicionarse como dirección nacional del a Jota" 41 .

Como es la tradición comunista, el representante máximo del conglomerado se escogió durante el Congreso Nacional, vale preguntarse: ¿por qué fue removido Salinas? En una entrevista en El Siglo, Núñez esclarecía este punto: "pensamos que el desarrollo actual del movimiento social, y en particular en el campo juvenil, nos impone nuevas exigencias. El desafío de los comunistas es no quedarnos atrás y menos ser quienes estanquemos la situación”, y agregó: "nuestro deber es estar a la altura de esas exigencias. Por ello hicimos cambios" 42 .

El año 1997 es importante en la historia de los gobiernos post Pinochet, ocupando un concepto emanado desde la JJ.CC. En voz de su nuevo secretario

\footnotetext{
${ }^{40}$ Contreras era el encargado universitario de la Jota en la clandestinidad y fue capturado por el Comando Conjunto en 1976. Luego de las torturas, los agentes los colocaban en las calles para que identificaran a sus compañeros. Contreras cumplió todo el rito de los torturadores, pero en el momento que se iba a juntar con el otro miembro de la dirección clandestina, se lanzó sobre un microbus y quedó seriamente herido. Alcanzó a gritar su nombre y denunciar que se encontraba secuestrado por el aparato represivo de la dictadura. Con esa acción, además de poner en aviso a su compañero y por tanto al Partido, cortaba el hilo que había permitido la aguda represión que vivía el PCCh en 1976. Mayor detalle revisar, Álvarez Rolando, Desde las sombras. Citado. El Siglo, "iJota jota...Ce...Ce!". Noviembre de 1994. P 12

${ }^{41}$ JJ.CC, "Informe de las Juventudes Comunista de Chile. Elaborado por la Comisión de evaluación". 15 de marzo de 1997.

${ }^{42}$ El Siglo, "La Jota con nuevo secretario". Mayo de 1997. P 9.
} 


\section{La reconstrucción: la Jota entre la marginalidad y el derecho a soñar (1994- 1999)}

general, se caracterizó por ser el año en que "se dan los primeros signos de fisuras al interior del modelo, que parecía una máquina imparable" 43 . Esta crítica tuvo su primer respaldo intelectual, cuando Tomas Moulian, a mediados de este año publicó un libro que se convirtió en lectura obligada para el militante de la Jota: Chile actual: anatomía de un mito. En ella, Moulian planteaba que el país era un resultado, "una producción del Chile Dictatorial". Sin pelos en la lengua, señalaba que el modelo chileno había convertido en el paraíso del consumidor, devorándose con ello las ideas transformadoras de una sociedad, quedándose en un cambio expansivo, liberal, móvil, pero sin historicidad. Una democracia que garantizaba la reproducción de un orden social basado en la propiedad y la ganancia privada; en la limitación de la acción colectiva de los asalariados y la tutela militar en política. En otras palabras -y aquí su idea central-: la democracia chilena no era tal, era un mito, ya que estaba protegida por distintos mecanismos heredados de la dictadura militar que denominó "jaula de hierro 44 ".

Además, la decisión aquel año del gobierno de Eduardo Frei de cerrar el mineral del carbón de Lota, provocó importantes manifestaciones de las familias mineras, muchas de ellas miembros del PCCh, que habría generado lo que Cristina Moyano llama la segunda renovación ideológica ${ }^{45}$. En ese mismo escenario, en la misma región, pero arriba en la cordillera, los inicios de la construcción de la represa hidroeléctrica Ralco, fueron semillas para que se radicalizaran las protestas del pueblo mapuche, encaminadas gradualmente a partir de Quinto Centenario. Ellas tendrían un vuelvo total en diciembre, cuando el incendio de los tres camiones en la comuna de Lumaco, marcaron un punto de ruptura en la historia del pueblo mapuche en su relación con el Estado chileno 46.

En mayo, la Universidad de Chile, bastión de la Jota y encabezada por Rodrigo Roco en la FECH, inició una movilización que se desplegó a lo largo del país. Si bien fue importante, ha quedado suscrita al recuerdo de sus protagonistas más que a una coyuntura o hito histórico ${ }^{47}$. Sin embargo, a partir de las continuas manifestaciones estudiantiles del siglo XXI, ha comenzado a ser resignificada, a partir de lo que Gabriel Salazar ha llamado como aquella "memoria social profunda", es decir, la trasmisión de las luchas y combates por el desarrollo y la igualdad"48. Esto último, ha sido trabajado desde una perspectiva historiográfica por Víctor Muñoz y Luis Thieleman. El primero desde una perspectiva generacional, mientras que el

\footnotetext{
43 El Siglo, "Las juventudes deben jugar un mayor rol de vanguardia”. Mayo de 1997. P 13.

44 Tomás Moulian, Chile Actual. Anatomía de un mito. Editorial LOM 1997.

45 Moyano Cristina, "El Partido Comunista y las representaciones del carbón: La segunda renovación”. En Revista Tiempo Histórico, UAHC, 2011

${ }^{46}$ Fernando Pairican, Malon. La rebelión del movimiento mapuche 1990-2013. Pehuen Editores, 2014.

47 Rodrigo Roco, “La FECH de fines de los 90: relatos de una historia presente". Revista Anales de la Universidad, № 17, 2005.

48 Gabriel Salazar, Poder Popular constituyente (siglo XXI). Ediciones LOM, 2011.
} 


\section{Fernando Pairican Padilla}

segundo, planteándola desde una perspectiva movimiental, donde los estudiantes se habrían convertido en la anomalía de la transición democrática ${ }^{49}$.

Lo cierto, es que las movilizaciones de estudiantes de 1997 tomaron un rumbo inesperado para sus protagonistas. Si bien ecos de movilización se habían producido a partir de 1994, ésta tomó ribetes que la Jota con algo de optimismo, llamó como la "rebelión estudiantil contra el neoliberalismo"50.

En efecto, dentro de las medidas tecnocráticas llevada adelante por el segundo gobierno de la Concertación, en el ámbito estudiantil dos reformas fueron vistas por los estudiantes de izquierda como la privatización del sistema educacional. Esto, para los jóvenes comunistas, demostraba la prolongación de la revolución capitalista del régimen de Pinochet. Una de ellas, emanada en 1995, conocida como Ley de Modernización, permitía la venta de bienes universitarios, con el fin de poder recaudar fondos, algo que era considerado por los estudiantes como responsabilidad del Estado. Esto último, permitía a las universidades pedir préstamos a la banca, con endeudamientos a costa de sus activos, "enajenando patrimonio de todos los chilenos", como escribió en una columna Daniel Núñez ${ }^{51}$.

La otra medida, que fue el hito que marcó la movilización de 1997, fue la creación de un nuevo sistema de créditos para los estudiantes de universitarios. Esta consistía en una asociación con la desmantelada CORFO, el motor productivo y económico de la República entre 1930 hasta 1979. Estos créditos, consistieron, en la posibilidad que los estudiantes de menores recursos, pudieran solicitar un préstamo bancario, siendo CORFO su aval. De alguna manera, era una bicicleta financiera, entre fondos privados y públicos. Esto, desde la perspectiva de la Jota, demostraba empíricamente que los gobiernos de la Concertación buscaban una "mejor aplicación del mismo modelo neoliberal"52.

Por todos estos antecedentes, por los distintos focos de protestas que se generaron en los movimientos sociales, Núñez planteaba que la batalla por la educación pública y la democratización de las universidades, no podía quedar suscrito a un ámbito gremial, era "parte de la lucha del pueblo chileno por democratizar nuestro país"53.

La prensa nacional, a principios de mayo comenzó a publicar noticias sobre el descontento universitario. El temor era que se iniciase un efecto dominó, como acabó por ocurrir. Así, de pronto las universidades estatales en Iquique, Antofagasta, Santiago, Concepción y Temuco, estaban paralizadas, comenzando a debatir las tomas de los campus en la espera de la cuenta pública del presidente. Una medida

\footnotetext{
49 Víctor Muñoz, Generaciones. Juventud universitaria e izquierdas políticas en Chile y México (Universidad de Chile-UNAM 1984-2006). Ediciones LOM, 2011; Luis Thieleman, La anomalía social de la transición. Movimiento estudiantil e izquierda universitaria en el Chile de los noventa (19872000). Editoras Tiempo Robado, 2016

50 El Siglo, "Rebelión estudiantil contra el neoliberalismo". Junio de 1997. P 3

51 El Siglo, "Rebelión estudiantil contra el neoliberalismo". Junio de 1997. P 3

52 JJ.CC, “Convocatoria X Congreso Nacional: Rebelarse es lo justo...rebelarse ahora...”. Diciembre 1998-julio 1999.

53 El Siglo, "Rebelión estudiantil contra el neoliberalismo".
} 


\section{La reconstrucción: la Jota entre la marginalidad y el derecho a soñar (1994- 1999)}

de fuerza que tenía como objetivo que se rechazaran las dos medidas de "modernización" que impulsaba el gobierno de Frei. Acusados por parte del Director de Carabineros, Fernando Cordero de terroristas, el presidente de la FECH, Rodrigo Roco respondía que eran una "organización estudiantil"54.

Ante la nula respuesta del gobierno en la cuenta pública del 21 de mayo, para la semana del 26 del mismo mes, se inició una "ola de tomas en las universidades" a lo largo del país. En total, 23 mil estudiantes se encontraban en estado de movilización, convirtiéndose en la principal fuerza de oposición al gobierno y al modelo económico. A los gritos de "el que no salta es rector", el "comezón estudiantil", tenía una adherencia de "60 mil universitarios en pie de guerra" para fines de ese mismo mes ${ }^{55}$.

Durante este proceso, la Jota se reunió en Valparaíso para desarrollar su IX Encuentro Universitario. Llegaron delegaciones a nivel nacional, las que volverían luego a sus centros de estudio a influir e impulsar las directrices comunistas el movimiento. La JJ.CC, demostraba en ese aspecto ser la organización mejor preparada y con capacidad de dotar con insumos ideológicos la movilización, nutriéndose con ello a la izquierda universitaria en su conjunto.

Janette Jara daba a conocer que su organización se había planteado ante la coyuntura ocupar todas sus energías en impedir la consolidación del modelo en la educación superior, en lo que llamaron como "el año decisivo", un guiño a la subjetividad de la PRPM, en referencia al supuesto año en que la dictadura se vendría abajo, en 1986. Como principal propuesta señalaban la creación de un arancel diferenciado. Este consistiría, en que los estudiantes de menores ingresos pagasen en base a sus posibilidades, lo que a su vez descendería las brechas entre los estudiantes con mayores recursos y los de menores ingresos. Era para Janette Jara "una propuesta de justicia"56.

Esta propuesta construida desde la Jota, fue recepcionada por el movimiento estudiantil, comenzando la militancia comunista a estudiar su viabilidad a partir de su impacto económico. Jara planteaba que el Estado tendría que "intervenir en la banda de precios de las carreras que se imparten", algo que aparecía como una propuesta muy dacial para el año en que el modelo no solo se estaba desplegando a nivel nacional, sino también, a nivel continental. Algunos autores a raíz de esto han llamado a los diez últimos años del siglo XX, como la "década pérdida"57.

Con todo, uno de los aspectos importantes de la movilización de 1997, fue recomponer el tejido organizativo del movimiento estudiantil. Para la quincena de junio, luego de un encuentro que aglutinó a cuarenta representantes de las direcciones universitarias a nivel nacional, se buscaron puntos de convergencia para

\footnotetext{
54 La Tercera, "Crece el descontento en las universidades". 9 de mayo de 1997; "ola de tomas en universidades". 26 de mayo de 1997; “avalancha de tomas en la Universidad de Chile”. 27 de mayo de 1997.

55 La Tercera, "Masiva y pacífica protesta de universitario". 31 de mayo de 1997.

56 El Siglo, "La plataforma que estamos levantando, la pelearemos y no se quedaran en palabras".

Abril de 1997.

${ }^{57}$ Carlos Salinas de Gortari, La década pérdida. Ediciones Debate, 2012.
} 


\section{Fernando Pairican Padilla}

fortalecer la demanda. La principal conclusión fue sobre el rol del Estado y su importancia como garante del derecho a que cualquiera persona pudiera estudiar, sin importar su condición económica. Comprensiva con los resquemores con estos postulados, Marisol Prado, secretaria general de la FECH, planteaba "la voluntad de generar una plataforma común", reconociendo que el centralismo afectaba las confianzas con las universidades regionales, sobre todo, la hegemonía de la Universidad de Chile ${ }^{58}$.

Esto último puso en relieve la incapacidad de la Jota de cruzar la barrera de la lucha gremial a una demanda universal, pero sobre todo forzar a la contradicción principal: derechos sociales versus neoliberalismo. En algún sentido, y que sería parte de la "derrota" de este movimiento estudiantil, fue la incapacidad de superar las desconfianzas entre las universidades regionales y las de la capital, estas últimas encabezadas particularmente por los comunistas. A nuestro parecer, el gobierno actuó a partir de impulsar la división en los estamentos universitarios, cuando Rodrigo Peñaililo, dirigente de la Universidad de Concepción, militante del PPD, comenzó a imponer un discurso regional antes que nacional, promoviendo las diferencias gremiales como principal foco. Aquello, dentro de otros aspectos, mostró la falta de maduración política de parte del movimiento estudiantil que acabó por romper la unidad que persistió entre mayo y junio. Sumado a ello, al interior de los propios campus, la Concertación movilizó a sus centros de estudiantes para provocar divergencias y forzar el fin de las movilizaciones. De alguna manera, el mes de julio se caracterizó por ser la ofensiva del gobierno a nivel nacional y local de sus propias fuerzas en el ámbito estudiantil ${ }^{59}$.

Esto fue acompañado por un cambio en el lenguaje y las ofertas de parte del gobierno, prometiendo mayores recursos para el sistema educativo. Se sumaron ante esto rectores y decanos, quienes propusieron instancias de negociación local para afectar la unidad de las movilizaciones. En este nuevo escenario, la Jota no tenía la capacidad de contrarrestar las fuerzas del gobierno, desarrolladas en tres ejes: Estado, decanatos y centros de estudiantes. Para mediados de julio, la prensa catalogó a las federaciones con hegemonía de la Jota como "el bando de los duros", mientras que los "blandos", acusaban presión del Partido Comunista, reflotando en su argumentación el anticomunismo, que era fuerte en el imaginario nacional, sobre todo en las organizaciones estudiantiles de la zona sur del país. Para mediados de julio, la CONFECH, entró en un proceso de acelerada ruptura. Rodrigo Peñailillo, acusaría al "señor Roco y la señorita Janette Jara", de desconocer los acuerdos firmados. En este nuevo contexto, el gobierno comenzó una ofensiva comunicacional, exigiendo el retorno a clases ${ }^{60}$.

Fue en Valparaíso, en específico en la Universidad de Playa Ancha, donde se escribió el capítulo final de esta historia. Por una votación de 29 votos de un total de

\footnotetext{
${ }^{58}$ El Siglo, "Este movimiento no se detendrá hasta lograr una reforma global del sistema universitario". Junio de 1997.

${ }^{59}$ La Tercera, "CONFECH resuelve hoy si negocia con el gobierno". 13 de julio de 1997.

${ }^{60}$ La Tercera, "CONFECH: disidentes plantean frente regional”. 16 de julio de 1997.
} 


\section{La reconstrucción: la Jota entre la marginalidad y el derecho a soñar (1994- 1999)}

32, ganó la postura de flexibilizar y comenzar a dialogar con el gobierno bajo sus propuestas, que estuvieron suscritas a una inyección económica de 14 mil millones de pesos en un plazo de tres años, en desmedro del piso de 24 mil millones que habían planteado los estudiantes. Abajo quedaban las políticas y demandas antineoliberales, de forzar al Estado a reconocer su rol como garante de la educación, la primera gran oleada de movilización estudiantil terminaba con una salida economicista, lejos de los ideales por los que la Jota trabajo en la reconstrucción del movimiento estudiantil.

El corolario de esta historia quedó escrito en la puerta de la federación de la Universidad de Valparaíso: "muerte a Cristián Cofré”, presidente de la instancia y acusado de haber negociado con el ala concertacionista de la CONFECH. Así acabó la primera explosión estudiantil, entre las críticas, atomizaciones y señales de descomposición en las relaciones humanas. El gobierno, había jugado sus cartas con tal precisión que la derrota fue aplastante, y para el Partido Comunista tuvo un doble impacto, cuando este conglomerado rechazó cualquier tipo de negociación electoral 61 .

Desde otra arista, la Jota había logrado pasar de ser una fuerza política marginal a ser un actor relevante a nivel nacional en 1997. Aquello sin duda era el principal logró, se cerraba los tiempos de la reconstrucción y de la sobrevivencia. En el aspecto ideológico, según Daniel Núñez, la victoria se suscribió a esclarecer la crítica de la juventud a una sociedad altamente consumista, individualista y conservadora. Que los obligaba a padecer a la fuerza el Servicio militar, que no abría los espacios laborales, y si estos se efectuaban, eran mal remunerados. Un conjunto de derechos humanos elementales, según el secretario general, se violentaban de parte del Estado. ¿cuál era el triunfo de estos destellos de rebelión juvenil? "rescatar la actividad política como expresión de los más nobles valores del ser humano, como son la solidaridad, la hermandad, la probidad, la entrega desinteresada por el prójimo, la honestidad y la trasparencia"62.

Un año después, en la convocatoria al X Congreso, momento en que la Jota evaluaba su política y preparaba sus estrategias para un nuevo periodo, se planteaba con satisfacción haber sido la vanguardia en la reconstrucción del tejido social y, de posicionar, al movimiento estudiantil como un acto político, "por cuanto las demandas de la movilización excedían ampliamente la reivindicación gremialeconomicista". Junto con ello, "al calor de las luchas universitarias se han desarrollado un importante número de cuadros, como también se ha fortalecido el rol de dirección de diferentes estructuras". Uno de los aspectos sin duda trascendental, fue que el "ala estudiantil" de la Jota podía, en vísperas del X Congreso, mirar con satisfacción su apuesta y Daniel Núñez, junto con su camada que había destronado a Guillermo Salinas, tiempo antes, llegar en una posición de hegemonía, ya que finalmente había contribuido de manera efectiva a la política

\footnotetext{
61 La Tercera, "no hay condiciones para un acuerdo con el PC". 14/10/1997.

62 JJ.CC, “Convocatoria”. Citado. P 3-10; El Siglo, "La propuesta de los jóvenes comunistas para los 90: una nueva forma de entender y hacer política”. Agosto de 1997. P 3.
} 


\section{Fernando Pairican Padilla}

general del Partido Comunista de implantar focos de rebelión al modelo. Dentro de ello, recuperar y dotar de contenidos ideológicos a la organización estudiantil, "uno de los pilares de los avances de nuestra política", señalaban en su Convocatoria.

Cerrado el capítulo del movimiento estudiantil, la Jota se abocó a preparar el acto cultural de conmemoración a uno de sus referentes políticos: Ernesto Guevara de la Serna. En base a su figura, celebraron el 5 de septiembre sus 65 años de la organización, desfilando por el centro de Santiago bajo la consigna: "Con el Che construyamos izquierda"63. Días después, Daniel Núñez escribía una verdadera oda al Che. Lo caracterizó como el revolucionario de tiempo completo, de absoluta convicción que guiaba a la Jota en sus objetivos; de una entrega desinteresada "en nombre de la dignidad humana", abandonando las tierras cálidas de Cuba y la burocracia, "para embarcarse en esta odisea interminable, que busca hacer más humano al hombre, y que estamos seguro arribaran a buen puerto". Guillermo Sherping, dirigente nacional del Partido Comunista, no se quedaba atrás. En nombre de "los viejos", destacando su consecuencia y la vigencia de sus postulados. La tarea del comunismo chileno era "forjar un pueblo de millones de hombres y mujeres capaces de ser como el Che"64.

Sin duda fue un acto multitudionario, con un Estado Nacional repleto de militantes, simpatizantes y cercanos al PCCh y que reunió a la familia de izquierda. Con una impronta latinoamericana, destacaron entre los principales artistas Daniel Viglietti, Silvio Rodríguez y Santiago Feliú, entre otros. Ángel Parra, cantautor chileno, aclaró apenas entró al escenario que esto no era una fiesta, sino una conmemoración, para dar inicio a capela su tema "soldadito boliviano", para luego dar paso al resto de artistas chilenos, vinculados a la Nueva Canción Chilena y al Canto Nuevo. Por siempre Che!, como la Jota bautizó al acto político-cultural, partió con un homenaje a uno de los referentes de los jóvenes comunista: Víctor Jara, interpretado por el grupo de Danza Espiral, los que ofrecieron al público dos temas de Jara, Cai Cai Vilu y el Aparecido, esta última, una de las más reconocidas composiciones del cantautor y dramaturgo, miembro de la Jota hasta su brutal asesinato en 1973.

A pesar de la derrota que la Jota tuvo frente al gobierno, fue un buen año. Aquello se ratificó en el plano de las elecciones universitarias, donde el comunismo volvió a triunfar en la Universidad de Chile como en la Universidad de Santiago de Chile, y tal vez, en un hecho inesperado, en base a una coalición denominada Estudiantes de Izquierda, por cerca de cien votos de diferencia con el gremialismo, triunfo el estudiante de teología Álvaro Ramis en la Universidad Católica. Esto era una demostración de confianza de un sector de los estudiantes a la izquierda, un triunfo de la apuesta de la Jota por politizar este sector y que le permitiría tener nuevamente representación en la $\mathrm{CONFECH}$, por ende, poner la agenda comunista durante el año 1998.

${ }^{63}$ El Siglo, “65 años de alegría y lucha”. 11 a 18 de Septiembre de 1997.

${ }^{64}$ El Siglo, "Hagamos que el ejemplo preceda a las palabras". Julio de 1997. 


\section{La reconstrucción: la Jota entre la marginalidad y el derecho a soñar (1994- 1999)}

Este sentimiento triunfalista lo reflejó la presidenta de la FECH, Marisol Prado, quien subrayaba la construcción de un nuevo movimiento estudiantil a partir de 1995, que había puesto la democratización y el derecho al acceso sin endeudamiento, como pilares fundamentales de la nueva política universitaria ${ }^{65}$. Álvaro Ramis, si bien independiente pero que había triunfado con el apoyo de la Jota, planteó que era un hito histórico y que marcaba el fin de la reconstrucción de la izquierda en la PUC, luego que la militancia socialista que dirigió la federación en 1993 terminase acusada de corrupción. A partir de 1998, señalaban que comenzaba una nueva izquierda, la que tendría por impronta con el gobierno de discusión y confrontación crítica de ideas ${ }^{66}$. Por su parte, Marcos Barraza, flamante triunfador en la FEUSACH, anunciaba que su conducción estaría caracterizada por la profundización de la lucha por los cambios sociales y por generar espacios de unidad para construir una nueva etapa. Desde su óptica, el triunfo de la izquierda general en el mundo universitario, respondía a un "fenómeno juvenil con proyección nacional" 67 .

Tal vez no erraba el dirigente en esto último. En las elecciones parlamentarias de fines de 1997, la lista "La Izquierda", encabezada por el Partido Comunista, había logrado un porcentaje de apoyo de 7,5\%, lo que sumado a un $2.9 \%$ del Partido Humanista, elevaba las cifras casi a un $10 \%$ de las preferencias. Era la mejor votación de la izquierda chilena a partir del retorno a la democracia. Para el PCCh, este porcentaje de apoyo, refutaba a todos los que "habían declarado" al comunismo chileno en "extinción"68.

A modo de síntesis de este apartado, la Jota logró convertirse en la primera fuerza política a nivel estudiantil y respondiendo en líneas generales a lo que el Partido Comunista demandó a sus fuerzas: avanzar en una revolución democrática, a partir de una ruptura democrática como resultados de rebeliones contra el sistema desde los movimientos sociales. La Jota, desde sus espacios de influencia, sobre todo en el ámbito estudiantil, lo había logrado a partir de una reconstrucción orgánica, comprendiendo los cambios, desafíos, y nuevas realidades de la juventud de mediados de los '90; perpetuando aspectos sustanciales de su tradición comunista, forjada en plena Guerra Fría, desempolvando uno de sus iconos (el Che) y posicionado las ideas políticas del comunismo en el debate nacional. Posiblemente por todas estas aristas, la desconfianza que existió en un primer momento por el supuesto "viraje hacia la derecha", por apostar por el mundo estudiantil, comenzaron a disiparse y, tal vez, como forma de reconocimiento, se le ofreció al dirigente máximo de la Jota, Daniel Núñez, un puesto para competir como diputado por el distrito 22 de Santiago. Era un reconocimiento desde la cultura comunista.

\footnotetext{
65 El Siglo, “Hoy estamos haciendo historia”. Octubre-Noviembre de 1997.

${ }^{66}$ La Tercera, "Izquierda dura y comunistas ganaron elecciones de la FEUC". 21/11/1997. P 20; El

Siglo, "En la UC ha triunfado la consecuencia de la izquierda". Noviembre de 1997.

${ }^{67}$ El Siglo, "vamos a profundizar las luchas por los cambios". Noviembre de 1997.

68 El Siglo, "El resurgimiento de la izquierda". Diciembre de 1997.
} 


\section{Fernando Pairican Padilla}

En una perspectiva más amplia, posiblemente Gladys Marín podía satisfactoriamente plantear ante sus críticos al interior del partido, como evaluación general, que los resultados electores y su hegemonía en el plano de los movimientos sociales, fue gracias a su apuesta por continuar con proyectar una línea de radical oposición a los gobiernos de la Concertación. Recordaba en una conferencia de prensa que por hacerlo, fueron acusados de estar fuera de la realidad, ser dogmáticos y no entender "que el mundo ha cambiado". La decisión, según ella, de escoger el camino más difícil de la derrota absoluta a la dictadura, "hoy día, a ocho años de gobierno de la Concertación, se ha demostrado absolutamente justo"69.

\section{“Mi derecho a soñar” 1998-1999: reflexiones finales}

"En tanto me anime un soplo de aire $Y$ en tanto me quede amor que entregar $Y$ en tanto me habite una gota de sangre Yo defenderé mi derecho a soñar (Francisco Villa, "Mi derecho a soñar")

"Los recientes triunfos consolidan a la izquierda como la primera fuerza dentro del movimiento estudiantil universitario", hacía hincapié Daniel Núñez en una entrevista para evaluar la contingencia a futuro como Jota. Ocho federaciones en manos de su organización, otras cuatro en poder de izquierda de carácter autonomista, mientras que la Concertación tenía una hegemonía en nueve, llevaron al secretario general a evaluar que los años venideros, estarían vinculados a la búsqueda de convergencia de las fuerzas antineoliberales. Políticamente, planteó que la hegemonía de las propuestas de la JJ.CC estaban logrando consolidarse, puesto que, en las campañas electorales de las federaciones, las mismas listas de la Concertación habían tomado la propuesta del arancel diferenciado como forma de abordar las diferencias sociales y comenzar a estrechar las diferencias de las desigualdades entre el estudiante de mayor y menor recursos. Esta propuesta política para la universidad era a su vez "una propuesta de país". ¿Cuál era esa propuesta como enseñanza desde el mundo universitario? la derrota en el ámbito a las "concepciones neoliberales dentro de los jóvenes". 70

A diferencia de los años anteriores, a partir de la movilización de 1997, emergió nuevamente una izquierda alternativa al comunismo, herederos de lo que se llamó a partir del triunfo de la revolución cubana en 1959, como la "nueva izquierda", que tuvo su mejor expresión en el MIR durante los sesenta y setenta. En el ámbito estudiantil, su expresión fue la SURDA, la que unió un discurso rupturista

\footnotetext{
${ }^{69}$ El Siglo, “Gladys Marín: Frutos de la política de rebelión”. 26 de diciembre de 1997.

70 El Siglo, "En las universidades asistimos a la derrota del neoliberalismo entre los jóvenes". Diciembre de 1997.
} 


\section{La reconstrucción: la Jota entre la marginalidad y el derecho a soñar (1994- 1999)}

con una construcción social desde abajo, logrando conquistar la presidencia de la Federación de la Universidad de Concepción.

Era el comienzo del fin del reflujo organizativo, luego de la derrota propiciada por los aparatos de seguridad de la Concertación durante sus primeros cuatro años. La Jota, a partir de 1998, afrontó por la izquierda a un nuevo "adversario", organizado en la ACME y la ETA, la primera en la universidad de Chile y la segunda en USACH. Daniel Núñez, reconociendo este fenómeno, en sus primeras entrevistas, seguramente en la búsqueda de alianzas para enfrentar al gobierno durante 1998, comenzó a hablar de las izquierdas, reconociéndoles su protagonismo y alejándose de cualquier estereotipos sobre esta nueva corriente, señalando que la división entre una izquierda tradicional y otra nueva, apuntaba a la división, "la izquierda es una: es la que pone hoy día, a través de un programa concreto, cambiar la realidad y propone una estrategia en cómo lograrlo"71.

Existía un consenso en las JJ.CC, de que los tiempos de reconstrucción del movimiento estudiantil habían llegado a su final. Ahora la tarea sería como llevar adelante la hegemonía comunista, sobre todo ante el brote de otra izquierda al interior de los recintos universitarios, ya que, para el comunismo, sus principales adversarios, las Juventudes Socialistas, estaban abiertamente fuera de combate. Por lo menos, ello demostraba las elecciones a federación, donde la Juventud Socialista había sido superada por la Democracia Cristiana y el PPD. Marisol Prado, de la FECH, denominó al año 1998 como de "desafíos", a lo que el vicepresidente de la FEUC, agregaba que, de no ser escuchados por el gobierno, enfrentaría un movimiento estudiantil "igual o más radical"72.

Sin embargo, entre 1998-1999, hubo un cambio en el escenario político. En el mes marzo el exdictador asumió como senador vitalicio y en octubre fue detenido en Londres. Parte del diseño institucional establecido por la dictadura llegó a su fin a manos de la justicia internacional. La detención de Pinochet, puso en relieve que el país estaba "muy lejos de sentirse reconciliado con su pasado"73.

En paralelo, durante estos dos años, la crisis asiática complementó el cuadro de dificultades para Eduardo Frei. La salida a esta recesión económica fue de corte neoliberal: restricciones sociales y elevando los costos de la vida cotidiana de clases las medias y bajas. Esto último tuvo una dificultad local, cuando las escasas lluvias afectaron la energía eléctrica del país, comenzado un proceso de restricciones, en algo considerado por la población como un bien "básico"74.

En este contexto, desde abajo, la emergencia de las movilizaciones sociales, comenzaron a ser articuladas detrás del antipinochetismo. Posiblemente, esto fue afectando el apoyo social al Partido Comunista, quienes las encabezaron al crear un

\footnotetext{
71 Ibíd.

72 La Tercera, "Balance de la FECH". 2 de enero de 1998. P 6; "Estudiantes están alertas por alza de aranceles". 16 de enero 1998. P 6.

73 Rafael Otano, Nueva crónica de la transición. LOM, 1995. P 455.

74 Álvaro Cobarrubias, "El manejo de la economía chilena frente a la crisis asiática 1997-2001". http://www.panorama.utalca.cl/dentro/2002-may/evolucioneconomica\%5B1\%5D.pdf.
} 


\section{Fernando Pairican Padilla}

Frente Amplio, que buscaba ser una coordinación política de izquierda, para ser una alternativa a la Concertación, la que cerraba una etapa de historia en 1999. A partir de ese año, los gobiernos de la Concertación comenzaría a tratar de "corregir" el neoliberalismo ${ }^{75}$.

No obstante, la irrupción de Joaquín Lavín, con un discurso despolitizador en lo referido a profundizar un Estado de derecho, y simplificando las discusiones políticas, fue otro factor determinante en la pérdida de hegemonía de la izquierda y el apoyo a la Concertación. Como dice Otano, "Lavín y su entorno fueron los primeros en entender que su antiguo héroe no proporcionaba ya votos, sino problemas". El resultado de ello, fue la despinochetización de Lavín y de la derecha en su discurso público, lo que le permitió disputar las presidenciales con Ricardo Lagos de una manera inesperada por los actores políticos. Para el Partido Comunista, como ha dicho Rolando Álvarez, la candidatura de Gladys Marín, marcó una esperanza, una ilusión que terminó en un fracaso ${ }^{76}$.

A sus 83 años, una de las voces respetadas al interior del conglomerado, Luis Corvalán, a pesar de su olfato político, no mostró ningún punto de acercamiento al momento político que estaba sucediendo a fines de 1999. Es más, subrayaba: "lo fundamental es luchar contra el sistema, crear conciencia y movimiento, crear una alternativa democrática, reconstruir la izquierda en este país". El PCCh y sus juventudes, se habían enamorado del apogeo de 1997.77.

Con todo, como ha planteado Rolando Álvarez, a partir del XXI Congreso, efectuado a fines de 1998, representó la consagración de cambios ideológicos y programáticos que lentamente se venían operando desde principios de la década. Es decir, tras el aparente renacimiento del estilo político de los años ochenta, el Partido Comunista consolidó su paulatina transformación ideológica. De alguna manera, la vocación electoral, la necesidad de ser pragmático, sin perder la radicalidad de los postulados (lo que no necesariamente los hacía popular), recuperaba uno de los aspectos sustanciales de la identidad comunista. Luis Corvalán señalaba: del comunismo "no ha sido nunca política de los comunistas abstenerse de las luchas electorales. Aunque sea para ser escuchados"78. Y arengaba sobre el diseño político que el PCCh prolongó para el nuevo milenio, "la Ruptura Democrática", que, según él, "apuntaba a desmantelar, aunque fuera de manera muy lenta y gradual, aquellos cerrojos $^{79}$.

\footnotetext{
75 Paul Drake e Iván Jaksic (comp.) El Modelo chileno. Democracia y desarrollo en los noventa. Editoral LOM, 1999; Camilo Escalona, Una transición de dos caras. LOM Ediciones, 1999; Manuel Antonio Garretón, Neoliberalismo corregido y progresismo limitado. Los gobiernos de la Concertación de Chile, 1990-2010. Ediciones ARCIS/CLACSO, 2012.

${ }^{76}$ Otano, citado. P 457. Sobre la política de Joaquín Lavín, el artículo de Verónica Valdivia, “La alcaldía de Joaquín Lavín y el lavinismo político en el chile de los noventa". http://historiapolitica.com/datos/biblioteca/chile ortizdezarate.pdf. Rolando Álvarez, citado. 77 La Nación, “Luis Corvalán 'aquí debe producirse un terremoto político"”. 1/11/1999. P 10-11 ${ }^{78}$ La Nación, citado.

${ }^{79}$ Tomás Moulian, Chile Actual. Anatomía de un mito. LOM Ediciones, 1997. Sobre el Partido Comunista en este periodo, el libro de Rolando Álvarez, Los hijos e hijas de la rebelión. Una historia política y social del Partido Comunista de Chile en postdictadura (1990-2000). Inédito.
} 


\section{La reconstrucción: la Jota entre la marginalidad y el derecho a soñar (1994- 1999)}

Para el caso del movimiento estudiantil, y, por lo tanto, para uno de los frentes principales de la Jota, los dos últimos años del siglo XX, estuvieron marcados por la consolidación de una coordinación de estudiantes, la CONFECH, que, para mediados de 1998, realizó su primer congreso de carácter programático. No estuvo exentos de disputas, sobre todo cuando la Concertación intentó quebrar nuevamente la instancia, no obstante, la izquierda no comunista y la Jota, mantuvieron el buque a flote. Para la dirigente Marisol Prado, marcaba un momento "refundacional", era el fin de la división del mundo universitario decretado por la dictadura militar en 1980, cuando dividió en pequeñas universidades estatales la educación pública ${ }^{80}$.

Es difícil dimensionar si existió un reflujo político, como afirma Thieleman, pues continuaron las movilizaciones durante los dos últimos años del siglo XX, si bien mermadas en apoyo de masas, estas crecieron en intensidad, sobre todo cuando debutó la violencia como instrumento en la medida que nacieron nuevas organizaciones. Tal vez, el hecho simbólico de esto se dio en 1999, cuando murió Daniel Menco en la Universidad de Tarapacá por un disparo de carabineros. A nuestro parecer, se consolidaba gradualmente otra izquierda en el ámbito universitario.

Si existió un reflujo, ello está a nivel de las propuestas políticas, los estudiantes no se englobaron por transformaciones profundas, sino, por medidas a corto plazo, en la inyección de recursos estatales al Fondo Solidario. En ese aspecto, mientras la propuesta de la Jota de implementar un arancel diferenciado, continuaba siendo una política acorde al momento político nacional, las otras izquierdas comenzaron a plantear la idea de gratuidad. Esto, puso en relieve que efectivamente la Concertación podía desmovilizar al movimiento estudiantil, pero era incapaz de conducirlo y menos de dotar de contenidos ideológicos la que efectivamente se mostró como una de las fracturas del modelo: el acceso y pago al sistema educacional.

A modo de cierre, me parece no se puede reducir la influencia de un conglomerado político netamente al plano de las ideas, sino, como se cruzan estos con los episodios nacionales en una perspectiva internacional, "sobre todo tratándose de una ideología y de un movimiento autodefinido como internacionalista"81. Como ha dicho Sergio Grez para los estudios sobre el comunismo, para poder historizar este conglomerado, debemos incluir aspectos como el "clima" cultural y político de la sociedad global en el que han actuado los comunistas, las tradiciones "heredadas" del movimiento popular, la composición de anhelos de su base social, la "cultura societaria" de la "familia comunista". En otras

\footnotetext{
${ }^{80}$ El Siglo, “El congreso estudiantil es el mayor hito histórico desde 1980”. Julio de 1998. P 4-5. 81 Ibíd.
} 


\section{Fernando Pairican Padilla}

palabras, "descubrir las condicionantes de la política por lo social y, a la vez, desentrañar las influencias de la política sobre lo social"82.

En esta perspectiva, como se ha planteado, efectivamente la historia del movimiento estudiantil durante la primera década del siglo XXI, no puede quedar suscrita a la hegemonía del Partido Comunista, como ocurrió en los últimos cinco años del siglo XX. Y posiblemente, esta "nueva" izquierda, como dice el autor, comenzó cada vez más a tener pugnas con el Partido Comunista ${ }^{83}$.

No obstante, este planteamiento corre el riesgo de reducir las perspectivas historiográficas. Si analizamos la historia de la Jota y de la izquierda estudiantil en base a dos temporalidades, es decir, por un lado la coyuntural, en la esfera de la cotidianeidad de la política y las efervescencias de los ritmos de la misma, posiblemente es posible apreciarlo de este modo. Pero si lo analizamos a partir de un marco temporal de más larga duración, incorporando aquella memoria social profunda como plantea Gabriel Salazar, se complejiza y complementan las perspectivas historiográficas. De alguna manera, si combinamos la corta y larga duración para comprender la trayectoria de la Jota, nos permite comprender la reconstrucción del movimiento estudiantil y, a su vez, lo paradójico, que para algunos fue el retorno del comunismo al escenario nacional a partir del 2011.

Desde el tiempo presente, mirando en perspectiva, efectivamente la Jota al unir una tradición comunista y adaptarla a las transformaciones del neoliberalismo corregido, les permitió perpetuar un imaginario de izquierda transformadora, crítica al capitalismo y los vacíos democráticos. Al ser una militancia si bien coherente entre sí, aunque lejos de esa imagen de un conglomerado sin pugnas, la Jota logró ser la organización juvenil mejor preparada para encabezar el movimiento estudiantil y dotar de contenidos ideológicos las críticas al sistema. Para ello, ocupó distintas tácticas políticas con el fin de revertir los cerrojos de la transición democrática, como la negociación, el pragmatismo, las protestas callejeras y una preparación a su vez teórica. En ese proceso, la movilización de 1997, les permitió capitalizar políticamente ese momento. Como se ha dicho, la Jota se convirtió en los fundadores de una cultura política de organización para el movimiento estudiantil en su conjunto, ya que posicionó la democracia como el eje central, lo que, visto desde el tiempo presente, fue una política radical.

Ello no era ajeno a la tradición comunista, la que, a diferencia de otros comunismos, siempre posicionó la democracia como el espacio de pugnas políticas. Su mejor experiencia, sin duda fue la Unidad Popular, a partir de ese imaginario, la Jota re-impulsó lo que llamaron como la Revolución Democrática. ¿por qué perdió esa hegemonía de conducción? Porque efectivamente, la otra izquierda, heredera de la "nueva izquierda" que se fundó a partir del triunfo de la Revolución Cubana,

\footnotetext{
82 Sergio Grez, "comunismo chileno e Historiografía: un par de observaciones". En Olga Ulianova, Manuel Loyola y Rolando Álvarez, (edit.) El siglo de los comunistas chilenos, 1912-2012. Ediciones IDEA, 2012. P 29.

${ }^{83}$ Luis Thielemann, Hijos de Recabarren, hijos de la transición: sobre las JCC y la anomalía estudiantil de los 90. En Un trébol de Cuatro hojas. Citado.
} 


\section{La reconstrucción: la Jota entre la marginalidad y el derecho a soñar (1994- 1999)}

terminó su ciclo de reflujo. No obstante, si miramos la agenda del movimiento estudiantil del 2011, sus brotes de movimientalidad que la antecedieron (2001 y 2006), de alguna manera fue la discusión que la Jota posicionó a lo largo de la década de los 90: garantizar derechos universales y el rol que el Estado debía cumplir como garante de ellas. Pero más allá, la Jota finalmente contribuyó a fortalecer, algo que acabaron por plantear a fines de 1999 en su X Congreso: "la contradicción principal es neoliberalismo v/s democracia". Aquella postura es justamente la que hoy se debate en el movimiento estudiantil al interior de Chile. Como ha planteó la hoy Ministra de SERNAM, Claudia Pascual, "hoy puede aparecer como algo evidente, pero en aquel tiempo al denunciar la privatización de la educación y el lucro, te trataban de loco" 84 .

Desde nuestra óptica, por lo tanto, nos parece que la hegemonía no se puede reducir a quien encabeza un movimiento en coyunturas particulares, sino, en cómo dotas de perspectivas ideológicas a un movimiento de transformación. En ese aspecto, el aporte central de la Jota fue lo antes señalado, pero también de encabezar la reconstrucción del movimiento estudiantil, dotarlos de componentes políticos y mantener nociones centrales del pensamiento de izquierda, lo que el trovador de la Jota, haciéndose eco de ese "Necio" que planteó Silvio Rodríguez, planteaba como el "derecho a soñar".

\section{Bibliografía}

Álvarez Rolando y Loyola Manuel, Un trébol de cuatro hojas. Las Juventudes Comunistas de Chile en el siglo XX. Ariadna, 2014.

Álvarez Rolando, Arriba los pobres del mundo. Cultura e identidad política del Partido Comunista de Chile entre democracia y dictadura. 1965-1990. LOM Ediciones, 2011.

Álvarez Rolando, Desde las sombras. Una historia de la clandestinidad comunista (1973-1980). Ediciones LOM, 2003.

Álvarez Rolando, Los hijos e hijas de la rebelión. Una historia política y social del Partido Comunista de Chile en postdictadura (1990-2000). Inédito.

Bravo Viviana, ;Con la razón y la fuerza venceremos! La rebelión popular y la subjetividad comunista en los '80. Ariadna, 2010.

Cobarrubias Álvaro, "El manejo de la economía chilena frente a la crisis asiática 1997-2001".http://www.panorama.utalca.cl/dentro/2002may/evolucioneconomica\%5B1\%5D.pdf.

${ }^{84}$ Rolando Álvarez y Manuel Loyola. Citado. P 307. 


\section{Fernando Pairican Padilla}

Drake Paul e Iván Jaksic (comp.) El Modelo chileno. Democracia y desarrollo en los noventa. Editorial LOM, 1999.

Escalona Camilo, Una transición de dos caras. LOM Ediciones, 1999.

Garretón, Manuel Antonio, Neoliberalismo corregido y progresismo limitado. Los gobiernos de la Concertación de Chile, 1990-2010. Ediciones ARCIS/CLACSO, 2012.

Grez Sergio, "comunismo chileno e Historiografía: un par de observaciones”. En Olga Ulianova, Manuel Loyola y Rolando Álvarez, (edit.) El siglo de los comunistas chilenos, 1912-2012. Ediciones IDEA, 2012.

Moulian Tomás, Chile Actual. Anatomía de un mito. Editorial LOM 1997.

Moyano Cristina, "El Partido Comunista y las representaciones del carbón: La segunda renovación”. En Revista Tiempo Histórico, UAHC, 2011.

Muñoz Víctor, Generaciones. Juventud universitaria e izquierdas políticas en Chile y México (Universidad de Chile-UNAM 1984-2006). Ediciones LOM, 2011.

Otano Rafael, Nueva crónica de la transición. LOM, 1995

Pairican Fernando, "La gran crisis: las Juventudes Comunistas de Chile defendiendo su identidad en tiempos de transición y renovación democrática 1989-1992". Revista Izquierdas, 2016.

Pairican, Fernando Malón. La rebelión del movimiento mapuche 1990-2013. Pehuén Editores, 2014.

Riquelme Alfredo, Rojo atardecer. El comunismo chileno entre dictadura y democracia. Ediciones DIBAM, 2009.

Roco Rodrigo, "La FECH de fines de los 90: relatos de una historia presente”. Revista Anales de la Universidad, № 17, 2005.

Salazar Gabriel, Poder Popular constituyente (siglo XXI). Ediciones LOM, 2011.

Thieleman Luis, La anomalía social de la transición. Movimiento estudiantil e izquierda universitaria en el Chile de los noventa (1987-2000). Editoras Tiempo Robado, 2016

Thielemann Luis, "Hijos de Recabarren, hijos de la transición. Sobre la JJCC y la anomalía estudiantil de los '90. En Álvarez Rolando y Loyola Manuel, Un trébol de cuatro hojas. Las Juventudes Comunistas de Chile en el siglo XX. Aridna, 2014.

Ulianova Olga, Manuel Loyola y Rolando Álvarez, (edit.) El siglo de los comunistas chilenos, 1912-2012. Ediciones IDEA, 2012. 
La reconstrucción: la Jota entre la marginalidad y el derecho a soñar (19941999)

\section{Fuentes}

La Nación 1994-1999.

La Tercera 1994-1999.

El Siglo 1994-1999.

Documentos JJCC y Partido Comunista 1990-2000.

Núñez Daniel, "El despertar del movimiento estudiantil y la crisis de la universidad pública". Tesis para optar a sociología. Universidad de Chile, 2003

\section{Entrevistas}

Daniel Núñez Marzo-abril 2016.

Ricardo Jara Enero 2016.

Jeanette Jara Mayo 2016.

Carla Peñaloza Septiembre 2016,

Recibido: 20/06/2017

Evaluado: 23/07/2017

Versión Final: 20/08/2017 